RESEÑA

\title{
Enseñar léxico en el aula de español. El poder de las palabras.
}

Herrera, F. (ed.)

Barcelona, Difusión, 2017

195 páginas

POR IVÁN PARDINA

UNIVERSIDAD AUTÓNOMA DE BARCELONA IvanLorenzo.Pardina@uab.cat

El libro que nos ocupa, editado por Difusión el pasado año 2017, es un compendio de 14 artículos de reputados especialistas del ámbito universitario y de la enseñanza de ELE como Paz Battaner (RAE), Marta Higueras (Instituto Cervantes), Ernesto Martín Peris y Encarna Atienza (Universidad Pompeu Fabra) o Dolores Chamorro, Alejandro Castañeda y Rosario Alonso (Universidad de Granada) que pretende, como dice Herrera (International House) en la nota del editor, recopilar un abanico amplio de acercamientos a las cuestiones de tratamiento del léxico tanto teóricos como prácticos, con el fin de mostrar una fotografía panorámica que recoja desde la imagen central de los estudios específicos del léxico en el aula, hasta las zonas más periféricas en las que el enfoque léxico ha dado sus frutos. Paz Battaner, prestigiosísima lexicógrafa, miembro de la Real Academia de la Lengua y autora del prólogo del volumen apunta que los autores de este libro se acogen mayoritariamente al enfoque léxico que Michael Lewis propuso en los años noventa y comenta algunos de sus principios teóricos para fijar de manera general el tema a tratar. Los 14 artículos que comprende el libro, como corresponde a la colección Cuadernos de Didáctica en la que la editorial lo ha ubicado presentan posibles aplicaciones de cómo llevar al aula actividades que potencien la adquisición del léxico de la forma más eficaz posible por parte del alumno.

El artículo de Marta Higueras que abre el volumen nos pone al día de los logros y avances conseguidos en aspectos esenciales de la enseñanza del léxico, gracias a la influencia del enfoque léxico de Lewis. También habla de los retos y del amplio camino todavía por transitar y termina describiendo cuáles deberían ser las habilidades de los profesores del siglo XXI. 
Le sigue el artículo de Ernesto Martín Peris que ahonda en las relaciones entre léxico y texto y ejemplifica la teoría que va desarrollando a partir de una columna de Juan José Millás. En su andadura va definiendo conceptos, como las metáforas conceptuales o los marcos de conocimiento, con ejemplos claros. El autor diferencia tipos de unidades léxicas y pone de relieve la importancia de prestar atención a fenómenos léxicos que van más allá del nivel de la palabra: combinaciones, unidades pluriverbales, fraseología o construcciones convencionales.

El artículo de Iñaki Tarrés trata también de estos fenómenos que nos hablan no solo del significado de una palabra en alguna de sus acepciones, sino también, como es propio del enfoque léxico, de la red de relaciones que se establecen con otras palabras, y aquí entran en juego las selecciones y las restricciones. Tomar conciencia de ello ayuda a acotar, dentro del gran océano que es el léxico, posibilidades reales, discriminar las que verdaderamente pertenecen a la lengua real de otras posibles pero no usadas. Y es por ello que deben pasar a formar parte del lexicón mental de los estudiantes. Sobre cómo organizar el aprendizaje de ese léxico aparentemente infinito $y$ de posibilidades ilimitadas nos hablan la categorización y la combinatoria. De ahí la importancia de un diccionario como Redes de Ignacio Bosque, que ayuda a entender esa complejidad de restricciones y combinaciones que permiten al estudiante adquirir competencia léxica de una manera significativa.

Anna Rufat y Francisco Jiménez Calderón describen cómo desde la irrupción de los enfoques comunicativos en la enseñanza y aprendizaje de lenguas, la adquisición de la competencia comunicativa ha pasado a ser el objetivo esencial de la enseñanza, lo que explicaría la preeminencia de la que goza actualmente el enfoque por tareas, que busca llevar al aula situaciones lingüísticas lo más similares posibles a aquellas en las que se encontraría un hablante nativo. En su artículo presentan aplicaciones de estos enfoques léxicos a la enseñanza comunicativa: reflexionan sobre qué vocabulario enseñar, qué factores influyen en su aprendizaje y qué fases seguir para tener éxito en su adquisición por parte del estudiante.

A su vez, José Luis Álvarez Cavanillas habla de dos manuales, las nuevas ediciones de Aula y Bitácora (Difusión, 2013 y 2016), que proponen materiales y actividades teniendo en cuenta un enfoque léxico, recogiendo resultados de investigaciones realizadas en este campo y prestando especial atención al eje horizontal de las unidades léxicas, en general a los denominados chunks o segmentos léxicos de extensión superior a la palabra como serían las colocaciones, los marcadores del discurso o las expresiones institucionalizadas. En ellos, aunque se atiende a la integración de las diferentes destrezas, se da especial importancia a las habilidades receptivas, especialmente a la comprensión auditiva. Se han aumentado significativamente las actividades en este sentido y se han enriquecido con 
documentos orales que incluyen diferentes variedades del español peninsular y del español de América. Se insiste en la enseñanza cualitativa del léxico y así podemos encontrar desde un Diccionario de construcciones verbales hasta epígrafes como La gramática de las palabras, Palabras en compañía o Palabras para actuar que presentan cuestiones léxicogramaticales, muestran colocaciones o trabajan expresiones institucionalizadas y marcadores del discurso, respectivamente, entre otros.

El artículo de Dolores Chamorro indaga sobre la forma de conseguir que el alumno tome conciencia, adquiera competencia léxico-semántica y consiga autonomía en su proceso de aprendizaje. Propone cambiar la perspectiva y quitar el foco de las palabras aisladas y ponerlo en el lenguaje formulaico, en los prefabricados, y da la mayor importancia a no reducir el conocimiento de una unidad léxica a su equivalencia en la L1 sino a crear conciencia en los alumnos de su relación con otras palabras, a su combinatoria y a su valor pragmático. Para ello hay que cambiar prácticas didácticas hasta ahora frecuentes y aplicar tipologías de actividades nuevas, y trabajar en la selección, presentación, explicación, organización y registro del vocabulario, diagnosticando las necesidades de los estudiantes para llevarlos de manera consciente un paso más allá en su habilidad para expresarse en español. El punto 4 presenta un valioso inventario de actividades concretas aparecidas en materiales didácticos editados.

Por su parte, María Cabot destaca varios principios del enfoque comunicativo relacionados especialmente con el léxico y presenta los diferentes estilos de aprendizaje del mismo para, seguidamente, presentar estrategias que tienen como objetivo tanto la asimilación del léxico como habilidades para aprender a aprender. Ejemplifica con una serie de actividades para que los alumnos sean conscientes de su estilo de aprendizaje, y para que aprendan y practiquen nuevas estrategias a fin de adquirir léxico de forma más duradera y rentable. Muchas de estas actividades trabajan diferentes tipos de significados (connotativo, denotativo, contextual, cotextual, etc.) y también diferentes relaciones entre palabras (hiperonimia, hiponimia, polisemia, etc.)

En su artículo, Verónica Ferrando trata específicamente del papel de las colocaciones en la enseñanza y el aprendizaje del español. En su artículo, tras mencionar que existen numerosas definiciones de estas combinaciones frecuentes de palabras, se centra en aquellas que resultan más útiles para la enseñanza de ELE y presenta la clasificación más detallada por su tipología que existe de ellas para el español. La idoneidad de abordar la enseñanza de las colocaciones ya desde los niveles iniciales, el tratamiento que de las mismas existe en los manuales de español y las principales herramientas que ayudan a trabajar la competencia colocacional en las clases, completan el artículo. 
Jon Andoni Duñabeitia, María Borragán y Aina Casaponsa hablan sobre los cognados en la adquisición y evaluación de segundas lenguas. Se trata de un artículo más técnico que informa de los estudios que, desde la neurociencia cognitiva del lenguaje y la psicolingüística se preguntan si en las diferentes fases de adquisición de segundas lenguas el uso de estas palabras cognadas, equivalentes por traducción y con gran solapamiento formal, coincidentes en varias de sus piezas puede convertirse en una herramienta diagnóstica y evaluativa a fin de valorar el conocimiento lingüístico que una persona tiene de dicha lengua. Los cognados pueden ayudar en los primeros estadios del aprendizaje de una lengua, ya que la ruta para recuperar su significado nos lo da el significante en la propia Lengua 1. Por el contrario, en estadios superiores, a medida que se profundiza en el léxico de la Lengua 2 y se establecen relaciones propias dentro de la lengua meta entre significados y significantes, los cognados pierden relevancia.

El artículo de Kris Buyse se centra en los corpus lingüísticos. Estos conjuntos de textos informatizados producidos en situaciones reales, que se han seleccionado siguiendo una serie de criterios lingüísticos que garantizan su uso como muestra representativa de lengua son importantísimos e imprescindibles ya que permiten detectar qué colocaciones son las más correctas o usuales, y qué segmentos de lengua suelen aparecer juntos formando unidades de sentido que facilitan considerablemente la comunicación. Si un estudiante de ELE es capaz de memorizar y usar correctamente estos segmentos de lengua se estará acercando cada vez más al uso real de la lengua que hace un nativo de ella. Su artículo nos informa sobre corpus existentes (CREA, CORDE, CORPES XXI, etc.), describiendo sus características y puntos fuertes. Su uso, aunque no siempre fácil, tiene muchísimo valor de cara a preparar las clases y también como posible herramienta para que los alumnos busquen de una manera guiada al principio y más autónoma después, información que les sirva, por ejemplo, para redactar mejor

Sergio Troitiño habla en su artículo de las implicaciones de crear materiales didácticos desde una perspectiva léxica y justifica la importancia del léxico indicando que el significado semántico es la base de la comunicación, que las lenguas tienen un carácter léxico y se procesan de manera léxica y que el léxico es una importante vía de acceso a la gramática, todo ello perfectamente ejemplificado y argumentado. Después, mediante una estructura bien pautada de preguntas y respuestas, nos acompaña en el proceso de seleccionar consciente e inteligentemente el léxico a programar para llevar al aula, teniendo en cuenta conceptos como la utilidad, la representatividad, la rentabilidad, la dificultad, etc.

Rosario Alonso Raya y Alejandro Castañeda hablan de la imposibilidad de disociar léxico y gramática, abogando por la integración 
de ambos mediante un tratamiento didáctico que reconozca tanto el valor relacional de los significados de las palabras como las restricciones léxicas de las reglas morfosintácticas. A modo de ejemplo presentan una secuencia de actividades pensada para trabajar los usos atributivos de ser y estar en su combinación con adjetivos de distintas clases semánticas y explican los criterios metodológicos aplicados en su elaboración.

El artículo de Encarna Atienza trata de la relación entre léxico y cultura e ideología, dejando patente que las palabras vehiculan cultura y concepciones del mundo distintas. Si de la elección de valiente o temerario para calificar a una persona se deriva una valoración positiva o negativa es la pragmática la que nos ayudará a explicar a los estudiantes de ELE estos fenómenos de parasinonimia, de voces de uso condicionado, de realidades idiosincrásicas o de unidades fraseológicas en las que se cuelan referentes socioculturales. El conocimiento de estos denominados pliegues de las palabras ayudará a entender la ideología que subyace, por ejemplo, en la elección entre inmigrante, emigrante, migrante o refugiado en un discurso, en un contexto concreto. Trabajar esto en el aula permitirá a los alumnos enriquecer su conocimiento de la lengua y les ayudará a ser más críticos y conscientes del poder y de la capacidad de influencia que las palabras tienen

Por último, Joan-Tomás Pujolà trata de la importancia de las nuevas tecnologías, y de nuevas aplicaciones para aprender y practicar vocabulario. Habla de cómo consultar palabras en la red analizando pros y contras de diferente buscadores, volviendo al uso de los corpus y enseñando cómo organizar el léxico en formato digital. También hace un repaso de aplicaciones o software en los que los estudiantes pueden practicar el vocabulario de manera autónoma.

A modo de conclusión, el volumen reseñado nos pone al día sobre la importancia de prestar atención a toda la información extra que las palabras nos proporcionan y llevar todo ello al aula con el fin de que los alumnos sean cada vez más autónomos y precisos a la hora de comunicarse y de usar el español como lo haría un nativo. Esta obra proporciona información teórica pero también práctica sobre cómo aplicar este enfoque léxico en la preparación de actividades y nos proporciona una gran cantidad de bibliografía específica. Una obra recomendable, útil e inspiradora para cualquier docente de ELE interesado en mejorar metodológicamente. 